\title{
UMA PROPOSTA DE RECONSTRUÇÃO DO CONCEITO, DOS COMPONENTES FUNCIONAIS BÁSICOS E DO MÉTODO DE ANÁLISE DA ORAÇÃO
}

\author{
CARLOS VINÍCIUS SILVA ${ }^{1}$, GISELA MÁRCIA MIARELLI PARDINI ${ }^{2}$. \\ 1 Graduando do curso de Letras Português/Inglês da Universidade Federal de Lavras (UFLA). \\ carlos.silva2@estudante.ufla.br. \\ 2 Graduando do curso de Letras Português/Inglês da Universidade Federal de Lavras (UFLA). \\ gisela.pardini@estudante.ufla.br.
}

\section{RESUMO}

O presente trabalho pretende, inicialmente, discutir os conceitos, primordialmente, de oração e, em segundo plano, de predicado, utilizados por Bechara (2009), Garcia (2007) e Perini (2011), demonstrando, de modo resumido, alguns problemas dessas concepções teóricas. Em seguida, este texto propõe-se a introduzir uma alternativa às visões gramaticais discutidas, construindo uma nova concepção de oração, elaborando novos elementos funcionais básicos para a oração que sejam detalháveis de modo tão ou mais coerente que as ideias de sujeito e predicado; estabelecendo um método quadridimensional de estudo da oração, ao invés do bidimensional saussuriano e estipulando uma fórmula de base para a análise sintática de orações da língua portuguesa, que, apesar de provavelmente ser aplicável a uma parte considerável das línguas orais humanas, não foi testada em outros idiomas, não podendo, portanto, a princípio, ser tomada como uma fórmula ampla. Como resultado das reflexões propostas neste texto, é esperado que sejam postos em dúvida, por parte da comunidade acadêmica, princípios gramaticais bem pouco questionados na atualidade, e, com isso, que seja iniciada uma discussão pertinente sobre esses princípios, que resulte na construção coletiva de uma nova fundamentação conceitual e uma metodologia atualizada de análise sintática condizentes com o que é esperado de um campo de estudos científicos complexo, que é a linguística. Dessa forma, a relevância deste artigo faz-se evidente tanto pela originalidade e pela coerência das ideias por ele propostas quanto por sua intenção de promoção de trabalhos coletivos para a reflexão sobre o caráter científico real da sintaxe e de outros objetivos de estudo da linguística dura.

Palavras-chave: Análise Sintática; Gramática; Orações.

\section{A PROPOSAL TO RECONSTRUC THE COCEPT, THE BASIC FUNCTIONAL COMPONENTS AND THE METHOD OF CLAUSE ANALYSIS}




\begin{abstract}
This paper aims to initially discuss the definition, primarily of clause, and secondly of predicate, used by Bechara (2009), Garcia (2007) and Perini (2011), demonstrating briefly some problems of these theoretical conceptions. This text then proposes to introduce an alternative to the grammatical views discussed, devising a new definition of clause; elaborating new basic functional elements for clauses which are equally or more coherently detailable than the ideas of subject and predicate; establishing a fourdimensional method of clause study rather than the Saussurian bidimensional method; and prescribing a parsing basic formula for the Portuguese language clauses, which, although likely to be applicable to a substantial number of human oral languages, has not been tested in other languages and therefore cannot in principle be taken as a broad one. As a result of the reflections proposed in this text, it's expected that a part of the academic community will put into question grammatical principles currently little questioned, and, with that, that a relevant discussion about these principles be initiated, resulting in the collective construction of a new conceptual foundation and an updated methodology of syntactic analysis consistent with what is expected from a complex field of scientific studies, which is linguistics. Thus, the relevance of this article is evident both from the originality and coherence of the ideas proposed by it as from its intention to promote collective works for reflection about the real scientific character of syntax and other study objectives of hard linguistics.
\end{abstract}

Keywords: Syntax Analysis; Grammar; Clauses.

\title{
1 INTRODUÇÃO
}

Durante os últimos três milênios da história ocidental, a gramática foi um dos focos principais dos intelectuais que se dedicaram aos estudos sobre o funcionamento das línguas orais humanas, e, dentro do grande escopo da gramática, um dos maiores objetos de estudo, se não o maior, foi a oração. No entanto, a oração, mesmo tendo tamanho destaque, manteve-se e, ainda, mantém-se como um conceito bastante controverso entre estudiosos. Esse problema deve-se ao fato de que a considerada mais importante unidade de análise sintática é produto direto da noção de proposição, muito utilizada na filosofia grega e que foi um ponto fundamental para o surgimento da lógica como a conhecemos hoje, sendo que as proposições, para funcionarem bem como ferramenta lógica, exigem, semanticamente, serem passíveis de falseabilidade e, sintaticamente, serem construídas sob estruturas específicas, típicas da modalidade escrita da língua, que claramente não abrangem uma parte significativa das 
possibilidades estruturais linguísticas. Dessa forma, a oração derivada da proposição gerou uma tradição prescritiva de construção gramatical que perdura até os dias de hoje, inclusive, ironicamente, nas chamadas gramáticas descritivas, na forma de, entre outras coisas, limitações equivocadas ou excessivamente restritivas das estruturas da fala humana real.

Tendo tal problema milenar em vista, o presente trabalho pretende elaborar uma alternativa plausível à tradição gramatical mencionada acima, buscando, respectivamente, (a) explicitar os pontos fracos dos conceitos de oração e predicado atuais, (b) introduzir um conceito de oração mais funcional do que os atualmente vigentes, (c) reclassificar os constituintes funcionais básicos da oração, (d) possibilitar a análise sintática em mais de duas dimensões, ao propor um rompimento com as limitações dimensionais oferecidas pela tradição de análise focada na modalidade escrita das línguas, o que dará à oração mais funcionalidade como objeto de análise, e (e) estabelecer uma fórmula basilar capaz de, fundamentalmente, constituir qualquer oração em língua portuguesa e, potencialmente, ser adaptável ao ponto de acercar todas as orações possíveis em qualquer língua oral humana, transformando a ideia de oração em uma ferramenta linguística e matemática que não só contemple toda a comunicação oral vigente como também preveja as possibilidades não exploradas dessa comunicação. Para isso, os procedimentos utilizados serão os de (1) apresentação e desconstrução dos conceitos e preceitos de oração vigentes, (2) desenvolvimento e fundamentação de uma nova proposta de análise do funcionamento das orações e (3) discussão e exemplificação da nova proposta.

\section{SOBRE OS CONCEITOS DE ORAÇÃO PRESENTES NAS GRAMÁTICAS BRASILEIRAS ATUAIS}

Como é sabido, embora a origem histórico-metodológica da oração seja a proposição (quando, na verdade, o ideal seria o contrário, haja vista que a proposição pode perfeitamente ser encaixada como uma categoria específica de oração), a oração pode, de modo mais verossímil, ser considerada uma subclasse de frase, que, por sua vez, é uma classe de enunciado. Por isso, para compreender o conceito de oração atualmente vigente, faz-se necessário, antes de qualquer outra coisa, compreender a ideia de enunciado, que, para Bechara, constitui-se da seguinte forma: 
Toda manifestação da linguagem com vistas à comunicação com nossos semelhantes se constrói com uma sequência de unidades delimitadas por um silêncio que precede o início dessa atividade e o que se lhe segue, acompanhada de contorno melódico, também chamado curva de entoação e normalmente marcada, na escrita, pelos sinais de pontuação e pelo emprego da maiúscula inicial [...]. A esta unidade linguística que faz referência a uma experiência comunicada e que deve ser aceita e depreendida cabalmente pelo nosso interlocutor se dá o nome de enunciado ou período (BECHARA, 2009, p. 406).

Esse conceito de enunciado apresentado por Bechara - que se faz lúcido e bastante aceitável, haja vista que abarca a maior parte, se não a totalidade, das comunicações humanas orais e escritas tomadas como ideais - possibilita a apresentação do segundo conceito importante para a reflexão sobre as orações, que são as frases, que, para o mesmo autor, são os enunciados cuja estrutura "não apresenta relação predicativa. São às vezes simples palavras, outras vezes uma reunião delas, que são transpostas à função de enunciado.” (BECHARA, 2009, p. 407).

Esse segundo conceito advindo de Bechara, mesmo estando parcialmente correto ao eximir a frase da obrigação da construção da relação predicativa, apresenta um problema, que é dar a entender que a frase necessariamente deixa de apresentar relação predicativa, o que faz com que frase e oração sejam conceitos estruturalmente distantes. Nesse aspecto, a concepção de frase de Garcia, apesar de também ter seus problemas, torna-se mais válida que a de Bechara:

\footnotetext{
Frase é todo enunciado suficiente por si mesmo para estabelecer comunicação. Pode expressar um juízo, indicar uma ação, estado ou fenômeno, transmitir um apelo, uma ordem ou exteriorizar emoções. Seu arcabouço linguístico encerra normalmente um mínimo de dois termos - o sujeito e o predicado - normalmente, mas não obrigatoriamente, pois, em português pelo menos, há, como se sabe, orações ou frases sem sujeito: Há muito tempo que não chove (em que há e chove não têm sujeito) (GARCIA, 2007, p. 32).
}

Sob a concepção de frase de Garcia, tem-se a correção do distanciamento proposto por Bechara, mas, em contrapartida, a criação do extremo oposto, que é a equivalência entre frase e oração, tornando a própria concepção de oração aparentemente desnecessária. Além disso, o gramático traz a suposta exceção como parte constituinte do conceito, o que, por si só, já explicita a inadequação concebida, a de que a frase necessita da relação predicativa. Dessa forma, faz-se válido entender que as duas noções de frase apresentadas são complementares, sendo passíveis de serem unidas, de modo coerente, em: "Frase é todo enunciado suficiente por si mesmo para estabelecer comunicação" e que pode apresentar ou não relação predicativa. 
Após discutir a ideia de frase, faz-se possível alcançar o conceito principal, e mais problemático, a ser discutido neste texto, o de oração. Para Bechara, "A oração se caracteriza por ter uma palavra fundamental que é o verbo (ou sintagma verbal) que reúne, na maioria das vezes, duas unidades significativas entre as quais se estabelece a relação predicativa - o sujeito e o predicado" (2009, p. 408). Essa visão corresponde exatamente ao que a gramática tradicional interpreta como oração, uma vez que, sob esse molde, uma oração constativa segue as regras da elaboração de proposições lógicas. Entretanto, essa concepção apresenta a simplificação excessiva da ideia de predicado, que corresponde a tudo que não é sujeito, como se todas as informações próximas do verbo e que não são o sujeito fossem modificadores diretos do verbo. Além disso, Bechara (2009), ao utilizar a locução adverbial na maioria das vezes, diz que existem casos em que a oração permite a não existência de um sujeito ou de um predicado, o que, como será explicado mais adiante, é uma ideia equivocada.

Já sob a visão de Garcia, influenciada pela noção equivocada de frase do autor, apresentada acima, a

\footnotetext{
Oração, às vezes, é sinônimo de frase ou de período (simples) quando encerra um pensamento completo e vem limitada por ponto final, ponto de interrogação, de exclamação e, em certos casos, por reticências. [...] Mas nem sempre oração (diz-se também proposição) é frase. Em "convém que te apresses" há duas orações, mas só uma frase, pois somente o conjunto das duas é que traduz o pensamento completo; isoladas, constituem simples fragmentos de frase, pois uma é parte da outra: "que te apresses" é sujeito de "convém" (GARCIA, 2007, p. 32).
}

Esse ponto de vista apresenta um problema ainda mais grave que o de Bechara (2009), já que tem como base a modalidade escrita da língua, que é essencialmente artificial e carregada de prescrições. Além disso, não ficam claras quais características da frase deixam de ser adotadas pela oração, haja vista que a oração, por ser uma subcategoria, não abarca todas as características da frase, ou seria, sempre, uma frase. Poder-se-ia, considerando a discussão feita até o momento, dizer que, seguindo a lógica do conceito de frase montado a partir das ideias de Bechara (2009) e Garcia (2007), a oração poderia ser "todo enunciado suficiente por si mesmo para estabelecer comunicação" (GARCIA, 2007, p. 32) e que, necessariamente, apresenta uma relação predicativa; e essa, de fato, seria uma conceituação plausível para os preceitos da GT. No entanto, como já foi dito anteriormente, há problemas com a noção de predicado, o que anula, também, o conceito de oração montado. 
A partir da análise feita acima, construída ao redor de textos de dois dos mais conceituados gramáticos da contemporaneidade brasileira, torna-se coerente dizer que a gramática tradicional, apesar de definir bem a ideia de enunciado e de apresentar ideias de frase que, quando unidas, formam uma visão bastante sólida, peca ao conceituar a oração. No entanto, para fins de esclarecimento, há de se reconhecer que essa não é uma exclusividade da GT, estando presente, também, em gramáticas descritivas. Prova disso pode ser encontrada em uma das obras mais importantes de Perini, "Gramática descritiva do Português", na qual, fazendo um trajeto semelhante ao de Garcia (2007), o autor apresenta a frase, citando Mattoso Camara, como a "Unidade de comunicação linguística, caracterizada [...] do ponto de vista comunicativo - por ter um propósito definido e ser suficiente para defini-lo -, e do ponto de vista fonético - por uma entoação [...] que lhe assinala nitidamente o começo e o fim." (MATTOSO CAMARA, 1977, p. 122, apud PERINI, 2011, p. 61); e a oração como "uma frase que apresenta determinado tipo de estrutura interna, incluindo sempre um predicado e frequentemente um sujeito, assim como vários outros termos.” (PERINI, 2011, p. 61).

Com as concepções apresentadas por Perini (2011), pode-se ver a frase, sob a visão do autor, como uma unidade linguística de função comunicativa simples completa e distinguível auditivamente, o que é coerente do ponto de vista pragmático, mas, do ponto de vista sintático, não tão apropriado quanto as conceituações anteriormente apresentadas. Já a ideia de oração estabelecida pelo ponto de vista de Perini não estabelece a predicação como uma condição de existência para a oração, tendo em vista que ele dá a entender que a oração nem sempre possui um sujeito. Além disso, o “determinado tipo de estrutura interna" (2011, p. 61) mencionado pelo autor não é detalhado de modo suficiente, resultando em uma fragilidade conceitual, e a insuficiência da concepção de predicado mantém-se.

Dessa forma, percebe-se que, pelo menos com base nas ideias dos três autores discutidos, os conceitos de oração presentes nas gramáticas prescritivas e descritivas não são suficientes para explicar a complexidade do principal objeto de estudos da sintaxe, problema que o presente artigo pretende resolver ou, no mínimo, amenizar.

\section{CONSIDERAÇÕES RECONSTRUTIVAS TEÓRICAS SOBRE O CONCEITO DE ORAÇÃO E DE SEUS COMPONENTES}


Como discutido acima, há inconsistências bastante consideráveis nos conceitos de oração tradicionalmente utilizados, além de o mesmo problema estar presente nos elementos funcionais da oração utilizados por esses conceitos - sujeito e predicado -. Em decorrência disso, faz-se pertinente construir uma alternativa potencialmente mais plausível a esses conceitos, o que não é possível em poucas palavras, pois a pura e simples condensação facilitaria o surgimento de novas deficiências. Assim, apresentarse-ão, abaixo, de forma topicalizada, aspectos fundamentais e complementares para a construção conceitual proposta, segundo o posicionamento dos autores do presente artigo:

1. A oração é uma estrutura sintática, portanto, matemática, cuja única condição de existência é a presença, implícita ou explícita, de todos os elementos funcionais básicos que a constituem.

1.1. Toda oração deve conter, implícita ou explicitamente, de modo concreto ou abstrato, um Referente, um Evento, um Localizador Espacial e um Localizador Temporal, que são os quatro constituintes funcionais básicos da oração.

1.1.1. Em uma oração, o Referente, tradicionalmente classificado como sujeito, é o ponto de referência pelo qual o Evento é comunicado.

1.1.2. Em uma oração, o Evento, tradicionalmente classificado como verbo central do predicado, é um acontecimento, dinâmico ou estático, que é comunicado a partir de um Referente.

1.1.3. Em uma oração, o Localizador Espacial é o elemento responsável por estipular o ambiente físico ou mentalmente compreendido como físico no qual um evento acontece.

1.1.3.1. O Localizador Espacial não pode ser considerado um elemento modificador para o Evento, pois o Evento, do ponto de vista sintático, continua sendo o mesmo independentemente do espaço.

1.1.4. Em uma oração, o Localizador Temporal é o elemento responsável por estipular o tempo em que um evento acontece.

1.1.4.1. O Localizador Temporal não pode ser considerado um elemento modificador para o Evento, pois o Evento, do ponto de vista sintático, 
continua sendo o mesmo independentemente do tempo em que acontece.

1.2. Cada um dos elementos básicos da oração pode ser subdividido em elemento principal, que pode ser linguisticamente marcado ou não (0) e que é essencial para a existência da oração; e qualificadores, que são elementos secundários, responsáveis por modificar ou especificar seus respectivos elementos principais, e que, quando existentes, são sempre linguisticamente marcados.

1.2.1. Em uma oração, o Referente pode ser subdividido em Referencial e Qualificadores de Referencial.

1.2.1.1. Em uma oração, o Referencial é o elemento principal do referente, essencial para sua existência.

1.2.1.2. Em uma oração, os Qualificadores de Referencial são os elementos que atribuem características modificadoras ou especificadoras ao referencial.

1.2.1.2.1. Em uma oração, os Qualificadores de Referencial não são essenciais para a existência de um referente.

1.2.1.2.1.1. Quando não houver Qualificadores de Referencial, marca-se essa inexistência com $(\varnothing)$.

1.2.2. Em uma oração, o Evento pode ser dividido em Fenômeno e Modificadores de Fenômeno.

1.2.2.1. Em uma oração, o Fenômeno é o elemento principal do evento, essencial para sua existência.

1.2.2.2. Em uma oração, os Qualificadores de Fenômeno são os elementos que atribuem características modificadoras ou especificadoras ao Fenômeno.

1.2.2.2.1. Em uma oração, os Qualificadores de Fenômeno não são essenciais para a existência de um Evento.

1.2.2.2.1.1. Quando não houver Qualificadores de Fenômeno, marca-se essa inexistência com $(\varnothing)$.

1.2.3. Em uma oração, o Localizador Temporal pode ser dividido em Tempo e Qualificadores de Tempo. 
1.2.3.1. Em uma oração o Tempo é o elemento principal do localizador temporal, essencial para sua existência.

1.2.3.2. Em uma oração, os Qualificadores de Tempo são os elementos que atribuem características modificadoras ou especificadoras ao Tempo.

1.2.3.2.1. Em uma oração, os Qualificadores de Tempo não são essenciais para a existência de um Localizador Temporal.

1.2.3.2.1.1. Quando não houver Qualificadores de Tempo, marca-se essa inexistência com $(\varnothing)$.

1.2.4. Em uma oração, o Localizador Espacial pode ser dividido em Espaço e Qualificadores de Espaço.

1.2.4.1. Em uma oração, o Espaço é o elemento principal do Localizador Espacial, essencial para sua existência.

1.2.4.2. Em uma oração, os Qualificadores de Espaço são os elementos que atribuem características modificadoras ou especificadoras ao Espaço.

1.2.4.2.1. Em uma oração, os Qualificadores de Espaço não são essenciais para a existência de um Localizador Espacial.

1.2.4.2.1.1. Quando não houver Qualificadores de Espaço, marca-se essa inexistência com $(\varnothing)$.

1.3. Nenhum dos elementos funcionais básicos da oração aparece duas ou mais vezes dentro de uma mesma oração.

1.3.1. Todo segundo Evento retratado, mesmo que indique um mesmo significado, implica uma nova oração.

1.3.2. Todo segundo Referente retratado, mesmo que indique um mesmo significado, implica uma nova oração.

1.3.3. Todo segundo Localizador Espacial retratado, mesmo que indique um mesmo significado, implica uma nova oração.

1.3.4. Todo segundo Localizador Temporal retratado, mesmo que indique um mesmo significado, implica uma nova oração. 
1.4. A falta de uma manifestação estritamente linguística para um dos constituintes básicos da oração não significa, de modo algum, que ele não esteja presente, pois a hierarquia entre os termos tende a resolver esse problema.

1.4.1. Diferente do que presumem as gramáticas tradicionais, a hierarquia entre os elementos funcionais da oração não pode se dar pelo critério de exigência, pois isso dá-se de forma arbitrária, uma vez que, dentro de uma oração, um elemento sempre exige o outro. Na verdade, a hierarquia dá-se pela capacidade que um elemento tem de indicar a existência do outro, por meio das concordâncias.

1.4.1.1. Para a concepção do eixo hierárquico, consultar o tópico 2.1.2.

1.4.1.2. Em uma oração, o Evento, elemento funcional básico hierarquicamente superior a todos os outros, tem potencial para indicar a existência dos três outros elementos; o Referente, que é o segundo na escala hierárquica, pode indicar a existência dos dois Localizadores; o Localizador Temporal, que é o terceiro superior, indica a existência do Localizador Espacial, uma vez que a existência do tempo é condicionada pela existência de um espaço fundamental, que seria a Existência ou Realidade; por fim, o Localizador Espacial é indicado pelos três outros elementos, haja vista que é condição de existência para eles.

1.4.2. Qualquer um dos elementos funcionais básicos da oração pode ser ocultado e, mesmo assim, estar presente, resultando em um vazio dotado de significado, ou, para utilizar uma nomenclatura esteticamente mais agradável, por um Zero Significativo (0).

1.4.2.1. Os zeros significativos possuem significados pragmáticos, mas que não são importantes para uma análise sintática.

1.5. Quando se tem usos múltiplos de apenas um, dois ou três dos constituintes funcionais básicos da oração (Referente, Evento, Localizador Espacial e Localizador Temporal), fazendo o reaproveitamento de todos os outros constituintes restantes, há a sobreposição de orações.

1.5.1. A sobreposição de orações é constituída quando uma oração é associada a outra(s) dentro de uma situação comunicacional dotada de duas ou mais 
orações, fazendo uso de elementos dessa(s) outra(s) oração(ões) para sua própria construção.

1.5.2. Os casos de aposto, por fazerem o reaproveitamento de elementos de uma oração principal para se construírem de modo econômico, constituem um caso de sobreposição de orações.

1.6. As orações, apesar de serem rígidas quanto à presença de seus elementos funcionais básicos, são flexíveis quanto à organização desses elementos.

1.6.1. Todos os constituintes funcionais básicos da oração são móveis, tornando a oração uma permutação de quatro elementos.

1.6.2. Todos os blocos de elementos internos dos constituintes funcionais básicos da oração (elemento principal + qualificadores) são móveis, tornando a oração uma permutação de $n$ elementos.

1.7. Ao contrário do que pressupõem as gramáticas tradicionais, em uma oração, a função de Evento, concebidas pelas GTs como verbo principal do predicado, não possui, por si só, a capacidade de suprir a função do Localizador Temporal, pois, para que isso seja possível, é necessário recorrer à análise semântica da oração, o que traz elementos culturais restritivos para a sintaxe, que, para ser estruturalmente compreendida, precisa ser concebida, ao menos em um primeiro momento, como uma construção pouco dependente de sentido.

1.7.1. A afirmativa feita em 1.7. implica que não é o Evento que determina o tempo da oração, mas sim o Localizador temporal que possibilita a concordância de tempo com o Evento.

1.7.2. Para sanar possíveis confusões, faz-se preciso dizer que o fato de o Evento indicar a existência de um Localizador Temporal não implica que o Evento dispensa a obrigatoriedade da presença do Localizador Temporal.

1.7.2.1. Para rever a ideia de Zero Significativo, consultar 1.4.2.

2. Toda oração é utilizada, dentro de culturas humanas, como instrumento de expressão linguística de um recorte de cena, concreta ou abstrata, em quatro dimensões, com foco em um evento ambientado física e temporalmente, a partir de um Referente. 
2.1. Quando se fala em quatro dimensões, considera-se que a sintaxe pode trabalhar com quatro eixos de análise, em vez de apenas dois, como presume a linguística saussuriana.

2.1.1. A primeira dimensão da sintaxe é o eixo sintagmático, que corresponde à organização linear e funcional horizontal dos elementos básicos da oração.

2.1.1.1. Essa primeira dimensão é bastante semelhante à proposta por Saussure e utilizada pelas gramáticas tradicionais.

2.1.2. A segunda dimensão da sintaxe deixa de ser o eixo paradigmático, haja vista que ele pertence à semântica, e passa a ser o eixo hierárquico, que corresponde à verticalidade da oração, possibilitando ver-se a hierarquia entre esses elementos.

2.1.2.1. Para consultar a ideia de hierarquia, consultar o tópico 1.4.1.

2.1.3. A terceira dimensão é a da profundidade, que determina o modo como uma oração relaciona-se com outra e com os elementos funcionais de outra, considerando que cada camada de profundidade apresenta apenas uma oração, mas que os elementos das orações são móveis entre as camadas. Desse modo, constitui-se o eixo composicional.

2.1.3.1. A partir da concepção do eixo composicional, faz-se plausível afirmar que todo conjunto de duas ou mais orações constitui sobreposição de orações.

2.1.3.1.1. Para consultar a ideia de sobreposição de orações, retomar o tópico 1.5.1.

2.1.4. A quarta dimensão da linguagem é o eixo temporal, que diz respeito à construção temporal da oração, ou seja, à ordem em que os termos surgem ou ressurgem no tempo.

2.1.4.1. A quarta dimensão presume que um elemento só é presente quando está sendo mencionado. Dessa forma, assim que o processo de fala ou de escrita termina de mencionar um elemento, ele passa a ser passado, dando espaço, no presente, para um novo elemento. No entanto, quando um elemento é retomado, de modo explícito ou implícito, a língua faz uma espécie de viagem no tempo, tornando um 
instante comunicacional do passado, presente por um novo breve momento.

2.1.4.2. A quarta dimensão oferece dificuldades para ser representada graficamente. Por isso, deve ser descrita, para a análise de uma oração isolada, como paralela à primeira dimensão, e, para a compreensão da relação simples entre duas ou mais orações, como paralela à terceira dimensão.

2.2. Para que haja oração, a função de Referência deve ser ocupada por um objeto concreto ou por um objeto abstrato sintaticamente indistinguível de um objeto concreto.

2.3. Como foi explicitado em 1.7.1, a obrigatoriedade da separação entre Evento e Localizador Temporal implica, necessariamente, na exigência de concordância por parte do Localizador Temporal, ou seja, quando há a flexão de tempo no Evento, é porque o Evento está concordando com o Localizador Temporal.

2.3.1. Todo Evento deve concordar em Tempo com o Localizador Temporal apresentado.

2.3.2. Como o Localizador Temporal tem o potencial de possibilitar a ocultação do Localizador Espacial como Zero Significativo, por aquele ter como propriedade a capacidade de indicar a existência deste, como foi dito em 1.4.1.2., há a necessidade da preocupação com a concordância de espaço. Entretanto, como a flexão de espaço, ao menos na língua portuguesa, não é marcada linguisticamente, sempre haverá a concordância.

3. O caráter interrogativo, declamativo, imperativo ou exclamativo da oração é dado por elementos exteriores à estrutura sintática propriamente dita da oração, podendo ser marcado por termos sem significado ou função sintática independente ou por variações tonais.

4. Interjeições podem ser frases, mas, por serem formas rudimentares de linguagem, apesar de boa parte delas contar com elementos tradicionalmente entendidos como pertencentes à linguagem complexa, não são parte constituinte de, ou são, por si só, orações.

4.1. Os vocativos, por funcionarem de modo muito semelhante às interjeições, não apresentam justificativa para não serem designados a essa classe de palavras. 
Portanto, vocativos, assim como outras interjeições, podem ser frases, mas não são partes de orações ou, por si só, orações.

5. Todos os elementos funcionais básicos da oração são ligados linguisticamente por operadores, que podem ser ocupados por significantes explícitos, manifestos pelos termos tradicionalmente chamados de preposições e conjunções, ou por zeros significativos (0) com função de preposição ou conjunção.

5.1. A regra apresentada em 5. é válida também para os componentes internos dos elementos funcionais básicos da oração (elemento principal e qualificadores).

5.2. Para retomar a concepção de Zero Significativo adotada, consultar tópico 1.4.2.

6. Sob as condições estabelecidas nos tópicos de 1 a 5 , as orações podem ser representadas pela fórmula resumida $\{[\mathrm{R}]+\mathrm{Ev}+[\mathrm{Le}]+[\mathrm{Lt}]\}$, que se esmiúça em $\left\{\left[\left(\mathrm{R}^{\prime}\right)+\left(\mathrm{QsR}^{\prime}\right)\right]+(\mathrm{F})+\mathrm{QsF}+[(\mathrm{T})+\mathrm{QsT}]+[(\mathrm{E})+\mathrm{QsE}]\right\}$.

6.1. Na fórmula resumida apresentada, $\mathrm{R}$ significa Referente.

6.1.1. Na fórmula esmiuçada, R' significa Referencial e QsR' significa Qualificadores de Referencial.

6.2. Na fórmula resumida apresentada, Ev significa Evento.

6.2.1. Na fórmula esmiuçada apresentada, F significa fenômeno e QsF significa Qualificadores de Fenômeno.

6.3. Na fórmula resumida apresentada, Lt significa Localizador Temporal.

6.3.1. Na fórmula esmiuçada apresentada, T significa Tempo e QsT significa Qualificadores de Tempo.

6.4. Na fórmula resumida apresentada, Le significa Localizador Espacial.

6.4.1. Na fórmula esmiuçada apresentada, E significa Espaço e QsE significa Qualificadores de Espaço.

6.5. Nas duas fórmulas apresentadas, + simboliza a presença de algum operador.

\section{EXPLICAÇÃO SOBRE A RECONSTRUÇÃO TEÓRICA PROPOSTA}

A construção conceitual elaborada acima, nos tópicos enumerados de 1 a 6 , traz, logo no primeiro tópico, a sintaxe para uma dimensão mais cerceada, limitada ao estudo da estrutura, o que implica que a oração é uma oração fazendo sentido ou não, e designando à semântica e à pragmática a compreensão dos significados práticos. Essa 
modificação possibilita que a sintaxe só precise atentar-se aos significados durante a elaboração dos conceitos apresentados no tópico 1. e durante a identificação dos seus constituintes .

Além disso, os constituintes funcionais básicos da oração, que, antes, resumiamse em sujeito e predicado, foram reestruturados pela proposta deste texto. Isso permite que o indivíduo que faz uma análise sintática não veja como modificadores do verbo todos os elementos que fazem parte do predicado, como objetos e complementos, passando a observar os localizadores de espaço e tempo como independentes do Evento, fatores de ambientação que não são parte constituinte de um suposto macroelemento chamado verbo.

Quanto ao tópico 2, expõe um mecanismo de análise sintática que busca a fuga da limitação bidimensional do papel, gerada pela tradição da análise da escrita. Para isso, esse tópico expõe três eixos posicionáveis no espaço, o sintagmático, o hierárquico e o composicional, e um eixo que, por conta de limitações físicas, não pode ser perfeitamente, por enquanto, demonstrado com precisão, o temporal. Com relação a essas dimensões, vê-se que o posicionamento no eixo hierárquico permite a identificação clara da hierarquia entre os termos da oração; que o eixo composicional possibilita a análise de orações subordinadas, de orações dentro de outras orações e de complementações colaborativas entre orações; e que o eixo temporal explicita o modo como o tempo interfere sobre o funcionamento da linguagem, demonstrando, inclusive, que a língua é uma eterna viajante do tempo. Desse modo, a visão da sintaxe em quatro dimensões cria uma ferramenta bastante eficiente para uma gramática realista e cientificamente atualizada.

Já nos tópicos 3 e 4, são esclarecidos problemas sobre aspectos que são considerados importantes para a sintaxe concebida pela tradição gramatical ocidental e que, de fato, são indispensáveis para o entendimento do funcionamento da língua, mas que, por serem consideráveis como pertencentes a uma linguagem rudimentar ou como recursos dependentes da cultura para serem compreendidos, não devem ser, a priori, objetos de estudo da sintaxe.

Por fim, nos tópicos 5 e 6, são explicitados os mecanismos de conexão interna da oração e uma fórmula funcional básica para análise sintática, que aparenta funcionar apenas para orações simples, mas que possibilita a formação de fórmula dentro de 
fórmula, ou seja, oração dentro de oração, de modo que a oração fragmento seja identificável como um dos elementos funcionais básicos da oração todo. Quanto à fórmula, poder-se-ia argumentar que os apostos tornam-na inválida. No entanto, é preciso considerar que o aposto, como foi dito em 1.6., é uma segunda oração que está localizada em uma camada de profundidade diferente da oração principal, mas que reaproveita elementos constituintes desta. Outro questionamento plausível seria o da impossibilidade de que um mesmo elemento apresente-se em duas posições diferentes dentro de um mesmo enunciado. Com relação a isso, há a necessidade de se considerar o eixo temporal da sintaxe, que impossibilita que dois termos sejam emitidos ao mesmo tempo, e, em contrapartida, permite que um termo movimente-se progressivamente ou multiplique-se dentro de uma oração, podendo ser apresentado em um dado instante e retomado a qualquer momento comunicacional.

\section{RECONSTRUÇÃO METODOLÓGICA DE ANÁlISE SINTÁTICA MOTIVADA PELO REVISIONISMO TEÓRICO PROPOSTO}

Para demonstrar a funcionalidade dos novos conceitos propostos, da terceira e da quarta dimensões mencionadas e da fórmula oracional elaborada, buscando aplicar todas essas novas noções, será feita uma análise do trecho abaixo:

Os vikings são uma antiga civilização originária da região da Escandinávia, que nos dias atuais compreende o território de três países europeus: a Suécia, a Dinamarca e a Noruega.

De início, faz-se necessário dividir o trecho em suas três orações e aplicar a fórmula oracional sobre elas, obedecendo a ordem em que os elementos funcionais são apresentados no texto original. Dessa forma, são criadas as seguintes estruturas:

Os vikings são uma antiga civilização originária da região da Escandinávia

$\left\{\left[\left(\mathrm{R}^{\prime}\right)+\left(\mathrm{QsR}^{\prime}\right)\right]+(\mathrm{F})+\mathrm{QsF}+[(\mathrm{E})+\mathrm{QsE}]+[(\mathrm{T})+\mathrm{QsT}]\right\}+$ $\{[$ Os vikings $+(\varnothing)]+($ são $)+$ uma antiga civilização originária da região da Escandinávia $+[(0)+(\varnothing)]+[($ dias atuais $)+(\varnothing)]\}+$ 
que nos dias atuais compreende o território de três países europeus:

$+\left\{[(\mathrm{T})+\mathrm{QsT}]+\left[\left(\mathrm{R}^{\prime}\right)+\mathrm{QsR}\right]+(\mathrm{F})+\mathrm{QsF}+[(\mathrm{E})+\mathrm{QsE}]\right\}+$

$+\{[($ dias atuais $)+(\varnothing)]+[($ a Escandinávia $)+(\varnothing)]+($ Compreende $)+$ o território de três

países europeus $+[(0)+(\varnothing)]$

a Suécia, a Dinamarca e a Noruega

$+\left\{[(\mathrm{T})+\mathrm{QsT}]+\left[\left(\mathrm{R}^{\prime}\right)+\mathrm{QsR} \mathrm{R}^{\prime}\right]+(\mathrm{F})+\mathrm{QsF}+[(\mathrm{E})+\mathrm{QsE}]\right\}$

$+\{[($ dias atuais $)+(\varnothing)]+[($ a Escandinávia $)+(\varnothing)]+($ compreende $)+$ a Suécia, a

Dinamarca e a Noruega $+[(0)+(\varnothing)]\}$

Em seguida, já com as estruturas básicas das orações disponíveis, pode-se montar imagens ${ }^{1}$ uni, bi e tridimensionais dessas orações, formando conjuntos de eixos, a fim de observar características que seriam mais dificilmente observáveis em um procedimento de análise sintática tradicional. Isso fica bastante claro nas imagens ${ }^{2}$ abaixo:

Imagem 1 - Par de eixos composicional-sintagmático

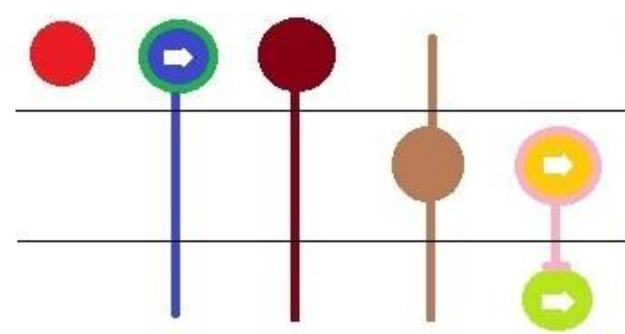

Os vikings são uma antiga civilização originária da região da Escandinávia (0), que nos dias atuais corresponde o território de três paises europeus: a Suécia, a Dinamarca e a

Eixo sintagmático

Nessa primeira imagem, que se refere ao par de eixos composicionalsintagmático, está representada a relação entre o eixo sintagmático tradicional, que

\footnotetext{
${ }^{1}$ Nas imagens, os elementos funcionais da oração foram substituídos por círculos coloridos, cada um referente à palavra de mesma cor, seguindo o padrão estabelecido na Imagem 1, para tornar a representação mais prática e econômica.

2 Pode-se ver que o círculo azul e verde, originado da primeira oração de cima para baixo da Imagem 1, gera uma ramificação azul que tem uma função diferente nas outras orações. Isso acontece porque "a Escandinávia", que faz parte do Qualificador de Evento representado pelo círculo mencionado, funciona como Referência para as outras duas orações. Esse recurso foi utilizado para resumir as informações presentes na imagem, sem, no entanto, gerar grandes problemas à ideia que se pretende apresentar.
} 
segue o vetor da escrita, da esquerda para a direita, e o eixo composicional, que constitui-se pela relação entre orações em profundidade, da frente para trás. Assim, a Imagem 1 demonstra a sentença em questão como que em um plano horizontal, em uma visão de cima para baixo. Nessa ilustração, pode-se ver claramente a ordem em que os termos das orações são apresentados, considerando que os círculos dentro de outros círculos são qualificadores dos elementos simbolizados pelos círculos maiores e que as setas brancas voltadas à direita indicam que o elemento principal antecede os qualificadores. Além disso, vê-se que, entre as três orações representadas, há o compartilhamento de elementos funcionais, ou seja, uma oração faz uso de elementos de uma outra para se completar estruturalmente, como previsto no tópico 1.5.1. mencionado anteriormente.

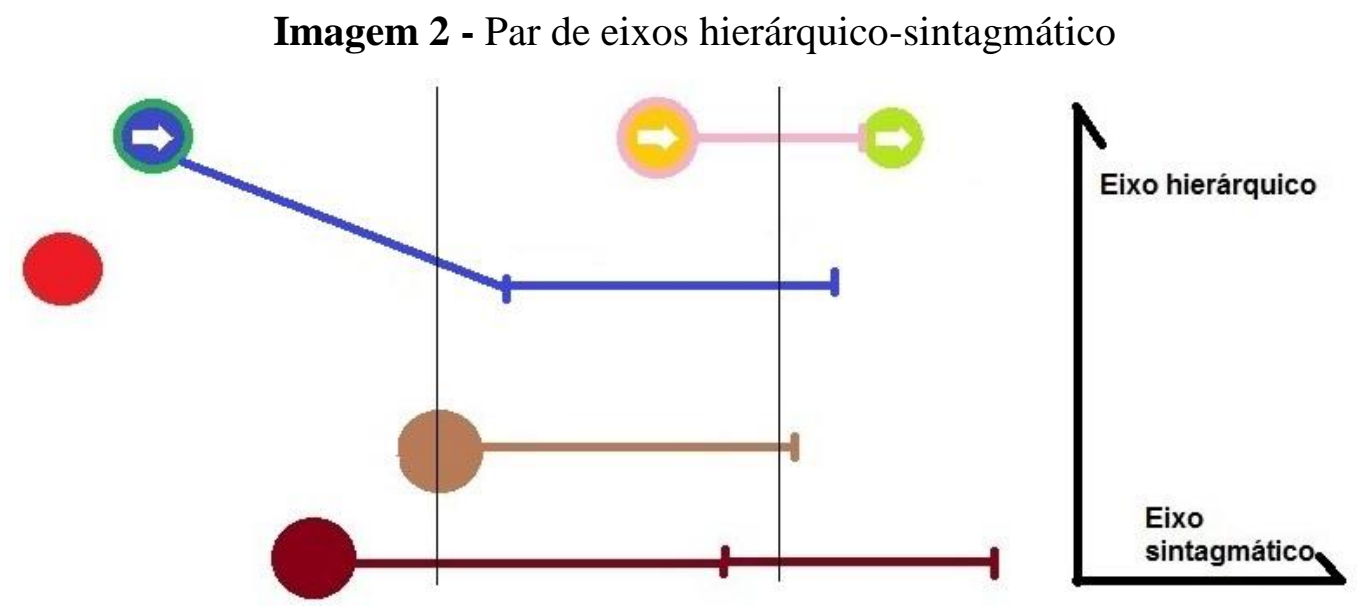

Já a segunda imagem, referente ao par de eixos hierárquico-sintagmático, diz respeito à observação da sentença em um plano vertical, como que desenhada em uma parede. Nela, traz-se, além da análise sintagmática, já vista na Imagem 1, a organização hierárquica dos elementos funcionais das orações analisadas, sendo que, de cima para baixo, os termos vão gradualmente perdendo poder hierárquico, seguindo os pressupostos do tópico 1.4. e de suas ramificações, ou, dito de outra forma, os eventos, que são hierarquicamente superiores aos outros elementos, estão acima destes, os referentes estão um nível abaixo, seguidos pelo Localizador Temporal e, por fím, pelo Localizador Espacial, sendo que esses dois últimos elementos apontados são compartilhados pelas três orações sob análise. 
Esse tipo de ilustração, associado aos apontamentos feitos no tópico 1.4.1.2., facilita a identificação dos elementos que podem transmitir as informações de outros, ganhando mais dessa capacidade conforme estão ilustrados mais acima e, portanto, são hierarquicamente superiores aos outros. Dessa forma, com as devidas adaptações morfológicas, o Evento da primeira oração, presente antes da primeira linha vertical traçada na Imagem 2, tem potencial para permitir a ocultação de todos os outros elementos da oração em que ela está inserida, assim como o Referente que o sucede verticalmente pode permitir a ocultação dos localizadores que estão logo abaixo dele, e assim por diante.

Imagem 3 - Par de eixos hierárquico-composicional

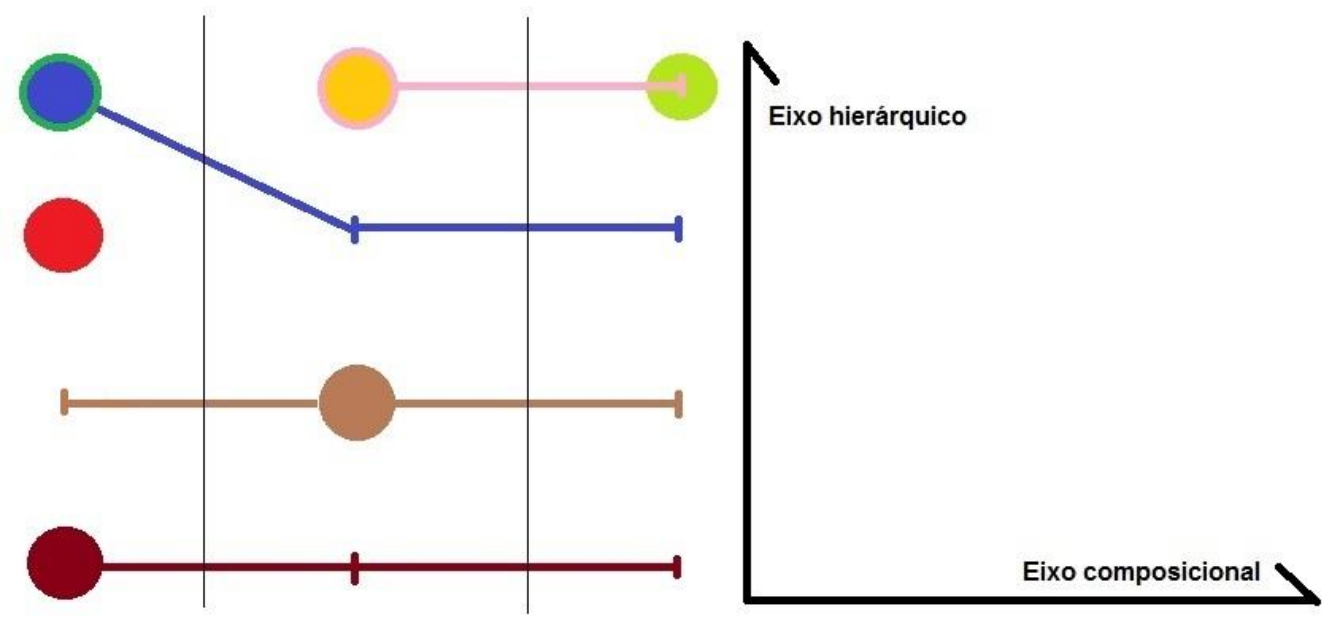

A imagem 3, que remete ao par de eixos hierárquico-composicional, representa os eixos hierárquico e o composicional, já retratados nas imagens 1 e 2, e analisam a sentença também em um plano semelhante a uma parede, mas perpendicular ao par de eixos hierárquico-sintagmático. Nessa ilustração, vê-se claramente que elementos pertencentes a diferentes orações, porém, de mesma função estão em um mesmo nível hierárquico, haja vista que estão em uma mesma linha horizontal. Além disso, vê-se facilmente, com o traçado de uma linha virtual, quais elementos pertencem a uma dada oração, sendo possível, inclusive, saber as funções de tais elementos apenas por meio da posição deles no eixo hierárquico. 
Imagem 4 - Trio de eixos hierárquico-composicional-sintagmático

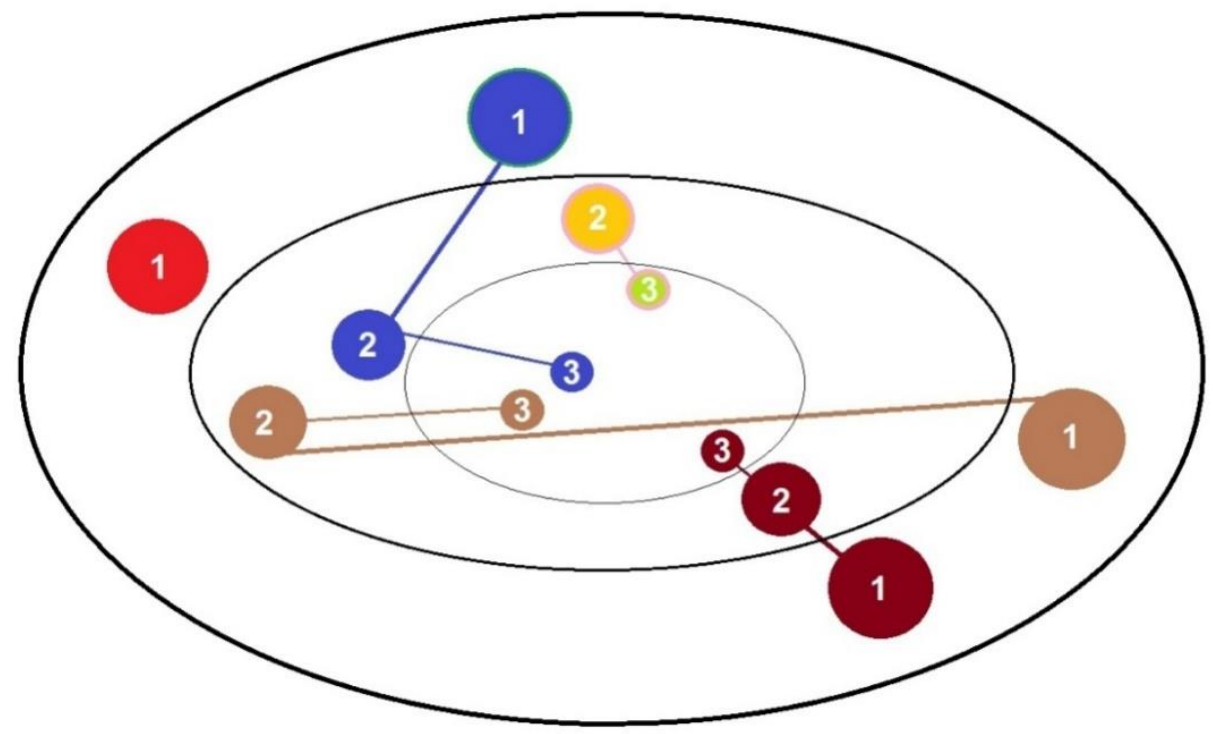

A soma das imagens 1, 2 e 3 resulta em algo semelhante ao que é representado na Imagem 4, sendo que a exatidão, até o momento, não é totalmente possível, haja vista que se trata da representação bidimensional do produto tridimensional resultante das outras três imagens. Entretanto, apesar dessa limitação, é possível perceber que a Imagem 4 possibilita a análise prática dos três eixos correlacionados, sendo possível identificar as informações emitidas por cada um desses eixos, de modo que cada camada circulada apresenta o par de eixos hierárquico-sintagmático e a divisão em camadas representa o eixo composicional. Nesse caso, é importante ressaltar que, idealmente, todas as camadas teriam o mesmo tamanho e um mesmo elemento funcional estaria sempre em uma mesma reta horizontal, mas isso provocaria a sobreposição de elementos, dificultando a compreensão total da imagem 4. 


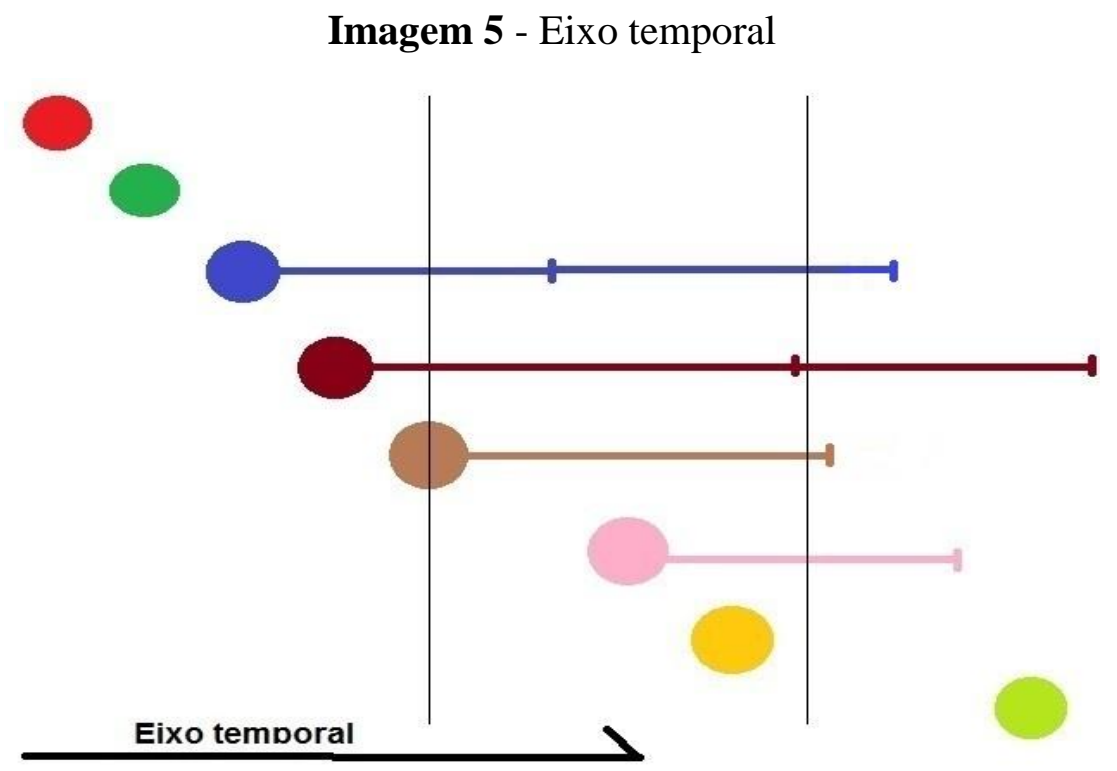

Por último, o eixo temporal, que, até o momento, não possui a possibilidade de constituição em pares, trios ou quarteto de eixos, por motivo semelhante ao apresentado pela imagem 4, permite a visão sobre o tempo em que os elementos funcionais da oração são mencionados e retomados, facilitando a identificação de relações sintáticas temporais entre orações, por mais distantes temporalmente que elas estejam umas das outras. Assim, caso, mesmo em um diálogo longo, um determinado vocábulo seja retomado, implícita ou explicitamente, é possível identificar facilmente de que momento desse diálogo o termo retomado advém.

Desse modo, com as cinco imagens acima, vê-se que as possibilidades de análise sintática geradas pelas quatro dimensões analisadas via mecânica de isolamento de pares e de trios de eixos são consideravelmente mais diversificadas e possibilitam a observação de um número bastante superior de características que a sintaxe tradicional, comprovando a aplicabilidade da proposta de análise desenvolvida no decorrer do presente texto.

\section{CONCLUSÃO}

O presente texto discutiu noções de oração utilizadas por gramáticas prescritivas e descritivas utilizadas atualmente, buscando demonstrar pontos falhos dessas noções. Em seguida, foi apresentado um novo conceito de oração e as implicações dele na 
gramática, que poderiam contribuir para a construção de uma metodologia de análise sintática mais detalhada que as da atualidade. Por fim, foi feita uma análise de trecho escrito real, utilizando os preceitos e as ferramentas resultantes da conceituação de oração apresentada no decorrer do texto, de modo que fosse demonstrada a funcionalidade da proposta em questão. Dessa forma, pode-se constatar que as ideias idealizadas pelo presente trabalho, apesar de muito provavelmente, por estarem em um estágio ainda inicial de desenvolvimento, apresentar um número bastante relevante de falhas, traz uma base consideravelmente sólida e que merece maior desenvolvimento.

\section{REFERÊNCIAS}

BECHARA, Evanildo. Moderna Gramática Portuguesa. 37. ed. Rio de Janeiro: Nova Fronteira, 2009.

DOLCE, Osvaldo; POMPEO, José Nicolau. Fundamentos de matemática elementar, 10: geometria espacial, posição e métrica. 6. ed. São Paulo: Editora Atual, 2010.

GARCIA, Othon Moacyr. Comunicação em Prosa Moderna. 26. ed. Rio de Janeiro: Editora FGV, 2007.

MLODINOW, Leonard. A janela de Euclides: A história da geometria, das linhas paralelas ao hiperespaço. 5. ed. 2010: Geração Editora, 2010.

PERINI, Mário Alberto. Gramática descritiva do português. 4. Ed. São Paulo: Ática, 2011.

SAUSSURE, Ferdnand de. Curso de Linguística Geral. 27. Ed. São Paulo: Editora Cultrix, 2006. 